\title{
INFLUÊNCIA DO TRATAMENTO DE DUPLO ENVELHECIMENTO DA SUPERLIGA INCONEL 718 SOB CONDIÇÕES DE FLUÊNCIA ${ }^{1}$
}

\author{
Fabrícia Assis Resende ${ }^{2}$ \\ Nathan da Cruz Lopes ${ }^{3}$ \\ Felipe Rocha Caliari ${ }^{4}$ \\ Danieli Aparecida Pereira Reis ${ }^{5}$ \\ Carlos de Moura Neto ${ }^{6}$ \\ Miguel Justino Ribeiro Barboza ${ }^{7}$
}

\begin{abstract}
Resumo
Com o avanço da tecnologia há necessidade de materiais que resistam a temperaturas elevadas e ambientes severos. A superliga Inconel 718 , a base de ferro-níquel, apresenta bom comportamento nestas condições. O tratamento térmico de duplo envelhecimento realizado no Inconel 718 propicia a precipitação de novas fases conferindo ao material maior resistência. Este trabalho tem como objetivo a Influência do tratamento de duplo envelhecimento da superliga Inconel 718 sob condições de fluência na temperatura de $700^{\circ} \mathrm{C}$ e tensão constante de $625 \mathrm{MPa}$. A amostra que sofreu o duplo envelhecimento apresentou melhor resistência à fluência, possivelmente devido ao aumento da dureza provocado pelo duplo envelhecimento.

Palavra-chave: Superliga; Inconel 718; Duplo envelhecimento; Fluência.

\section{INFLUENCE OF DOUBLE AGING HEAT TREATMENT OF THE SUPERALLOY INCONEL 718 UNDER CREEP TEST CONDITIONS}

\begin{abstract}
The advance of technology leads to produce best materials to be used in severe conditions of temperature and environment. The superalloy Inconel 718, based on iron-nickel, has good behavior under these conditions. The double aging heat treatment performed in Inconel 718 promotes the precipitation of new phases conferring greater resistance to the material. This work aims to study the influence of treatment of superalloy Inconel 718 double aging under conditions of creep test at $700^{\circ} \mathrm{C}$ and $625 \mathrm{MPa}$. The sample that suffered the double aging showed better creep resistance. Possibly because of the increased hardness brought about by the double aging.
\end{abstract}

Key words: Superalloy; Inconel 718; Double aging; Creep.

1 Contribuição técnica ao $68^{\circ}$ Congresso Anual da ABM - Internacional, 30 de julho a 2 de agosto de 2013, Belo Horizonte, MG, Brasil.

Engenheira de materiais. Escola de Engenharia de Lorena (EEL), USP, Lorena, SP, Brasil.

3 Ciências e Tecnologia. Universidade Federal de São Paulo (Unifesp), São José dos Campos, SP, Brasil.

4 Engenheiro químico, Doutorando, Universidade Federal de São Paulo (Unifesp), São José dos Campos, SP, Brasil.

5 Engenheira química, Professora Adjunta, Unifesp, Sócia Titular da ABM, São José dos Campos, SP, Brasil.

6 Engenheiro metalúrgico. Professor Associado, Instituto Tecnológico de Aeronáutica (ITA), Sócio Titular da ABM, São José dos Campos, SP, Brasil.

7 Engenheiro mecânico. Professor, Escola de Engenharia de Lorena (EEL), USP, Lorena, SP, Brasil. 


\section{INTRODUÇÃO}

A necessidade de materiais com maior resistência em temperaturas elevadas gera esforços no desenvolvimento de novas ligas estruturais e o aperfeiçoamento das ligas existentes.

O Inconel 718 pertence à família das superligas à base de níquel largamente usado em turbinas por apresentar alto ponto de fusão quando comparado às outras classes de materiais metalúrgicos comerciais e, a boa capacidade de operar continuamente em temperaturas elevadas. Apresenta também elevada resistência mecânica, resistência ao impacto, a fadiga, a fluência a corrosão e boa facilidade de forjamento e soldabilidade. ${ }^{(1)}$ Pode ser também utilizada na indústria criogênica, nuclear e petrolífera. ${ }^{(2,3)}$

O tratamento térmico de duplo envelhecimento é realizado com a intenção de precipitar mais que uma fase desejável visando o aumento da resistência mecânica pela precipitação dessas fases. ${ }^{(4)}$

Neste trabalho a superliga Inconel 718 foi submetida ao tratamento de solução sólida para homogeneização da microestrutura da amostra, a temperatura de $1.095^{\circ} \mathrm{C}$ por 1 hora, seguido do tratamento de duplo envelhecimento a $955^{\circ} \mathrm{C} / 1 \mathrm{~h}$, $720^{\circ} \mathrm{C} / 8 \mathrm{~h}+620^{\circ} \mathrm{C} / 8 \mathrm{~h}$. Os ensaios de fluência foram realizados na modalidade de carga constante na tensão de $625 \mathrm{MPa}$. A temperatura de $700^{\circ} \mathrm{C}$ foi utilizada devido a sua principal aplicação (materiais para turbinas a gás dos aviões a jato). Deve ser ressaltado que estudos completos de ensaio na fluência da superliga Inconel 718 com duplo envelhecimento são escassos na literatura.

\section{MATERIAIS E MÉTODOS}

\subsection{A superliga Inconel 718}

Para a realização deste trabalho foi utilizada a superliga Inconel 718 adquiridas junto à Villares Metals S. A. A superliga foi obtida por fusão em forno VIM, refusão em forno VAR, tratamento térmico de homogeneização, forjamento a quente em matriz aberta para desbaste, laminação a quente de desbaste e laminação a quente de acabamento.

A tabela 1 apresenta composição química, informada pelo fabricante, dos principais elementos mostrados em percentual em peso. Os valores informados atendem aos requisitos da norma American Petroleum Institute (API). ${ }^{(5)}$

Tabela 1. Composição química da superliga Inconel 718 , como recebido

\begin{tabular}{|c|c|c|c|c|c|c|c|}
\hline \multicolumn{1}{|c|}{ Concentração dos elementos } \\
\hline Elemento & Níquel & Cromo & Ferro & Nióbio & Molibdênio & Alumínio & Titânio \\
\hline$(\%)$ & 55,09 & 17,86 & 16,85 & 5,73 & 2,98 & 0,82 & 0,67 \\
\hline
\end{tabular}

Os corpos de prova foram confeccionados de acordo com as especificações mostradas na Figura 1. 


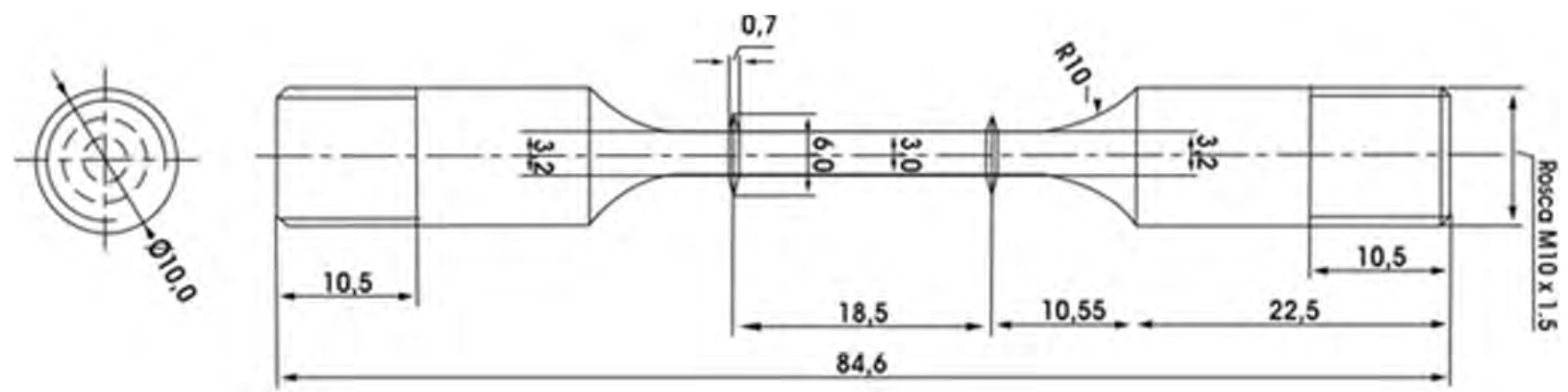

Figura 1. Desenho e dimensões do corpo de prova para ensaio de fluência. (dimensões em milímetros).

\subsection{Medidas de dureza - Microdureza Vickers}

As medidas de microdureza Vickers foram realizadas como parte da caracterização mecânica no intuito de comparar as mudanças nas características físicas do material sem e com o tratamento de duplo envelhecimento utilizando-se um microdurômetro Micromet 2004 da Buehler com uma carga de 100 gf durante 30 s, instalado na EELUSP. As medidas foram realizadas ao longo da seção transversal do material, devidamente fixado em baquelite, para melhor fixação e garantia da superfície perpendicular ao penetrador. Foram realizados 10 indentações, em cada amostra (com e sem o tratamento de duplo envelhecimento), com uma distância média de $20 \mu \mathrm{m}$ entre cada impressão evitando a possibilidade de alterações nas impressões.

\subsection{Tratamento Térmico de Duplo Envelhecimento}

A superliga selecionada, Inconel 718 , foi submetida tratamento térmico de solubilização a $1.095^{\circ} \mathrm{C}$ por 1 hora, seguida de tratamento de duplo envelhecimento a $955^{\circ} \mathrm{C} / 1 \mathrm{~h}-720^{\circ} \mathrm{C} / 8 \mathrm{~h}+620^{\circ} \mathrm{C} / 8 \mathrm{~h}$. Para realização do tratamento térmico utilizouse o forno refratário da marca Lindberg/Blue, no Departamento de Engenharia de Materiais da Escola de Engenharia de Lorena (Demar/EEL-USP). Tais tratamentos são mecanismos utilizados para o aumento de resistência da superliga Inconel 718, com a dissolução das fases de Laves e dos carbonetos na matriz.

A Figura 2 apresenta a rampa de aquecimento e resfriamento sofrido pelo material.

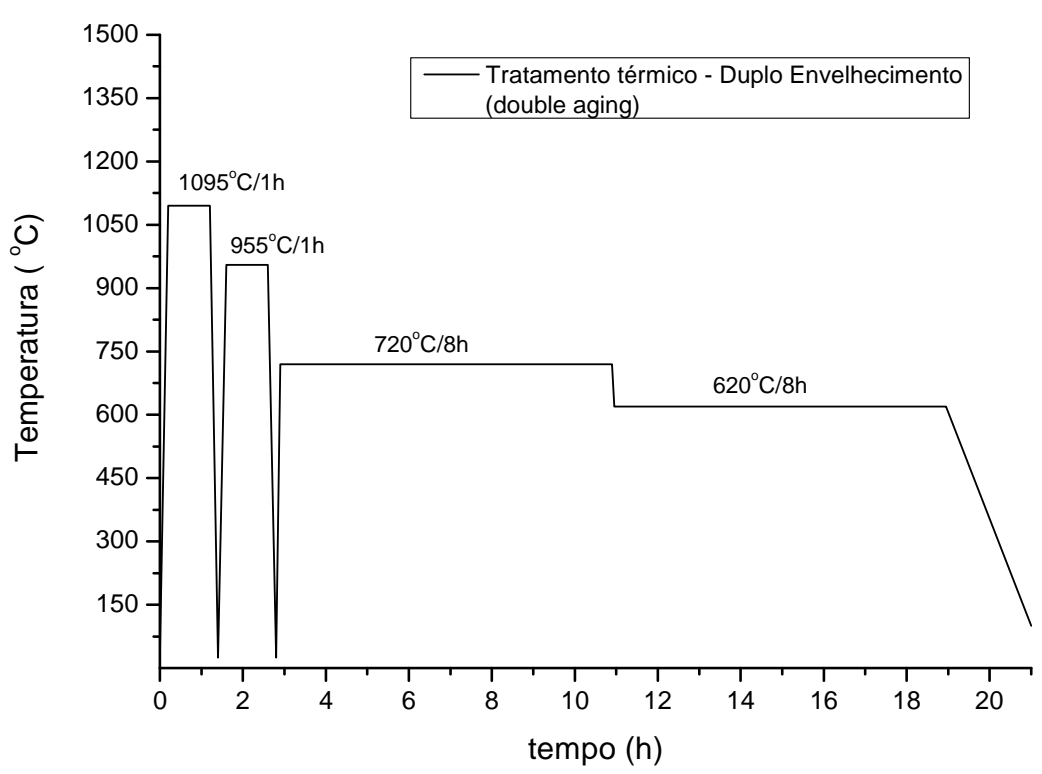

Figura 2. Etapas do tratamento de duplo envelhecimento. 


\subsection{Preparação Metalográfica}

A preparação das amostras para análise de microscopia óptica seguiram os padrões usuais de metalografia, ou seja, embutimento a quente $\left(150^{\circ} \mathrm{C}\right)$ sob pressão de 21 $\mathrm{MPa}$, seguido do lixamento manual com lixas à base de $\mathrm{SiC}$, na sequência de 320 , $400,600,1.200$ e 2.400 mesh. O polimento foi realizado com pasta de diante de 6 $\mu \mathrm{m}$. As amostras sofreram ataque eletroquímico com ácido oxálico 10\% para análise microestrutural. As imagens foram obtidas no microscópio óptico marca Leica modelo DMRXP do Instituto Tecnológico de Aeronáutica (ITA).

\subsection{Ensaio de Fluência}

Os ensaios de fluência foram realizados nos fornos pertencentes ao Instituto Tecnológico de Aeronáutica (ITA/DCTA), adquiridos junto à The Eletronic and Mechanical Engineering Co. Ltda. (EMEC). Nos fornos estão adaptados sistemas elétricos e controladores, desenvolvidos pela BSW Tecnologia, Indústria e Comércio Ltda., segundo as exigências da norma ASTM E139/11. ${ }^{(6)}$ Os dados relativos ao alongamento dos corpos de prova e as medidas de temperatura em períodos de tempo pré-determinados foram coletados pelo software Antares.

Para a alimentação do software, foram utilizados um calibrador de extensômetro de alta resolução Instron modelo 2602-004, e um transdutor do tipo LVDT (Linear Variable Differential Transformer) Schlumberger D 6,50, com especificação de 53,18 $\mathrm{mV} / \mathrm{V} / \mathrm{mm}$, à temperatura de aproximadamente $35^{\circ} \mathrm{C}$.

A superliga Inconel 718 foi analisada sob condições de fluência na temperatura de $700^{\circ} \mathrm{C}$ e carga constante de $625 \mathrm{MPa}$ em duas condições: como recebida e tratada termicamente com duplo envelhecimento para investigação da influência do tratamento sobre a vida em fluência da superliga.

\section{RESULTADOS}

\subsection{Tratamento Térmico}

A Figura 3 foi obtida via microscopia óptica e apresenta a estrutura microestrutural como recebida e após tratamento térmico de duplo envelhecimento, da superliga Inconel 718, respectivamente. Por meio dessas imagens não se pode observar a precipitação das fases de interesse, necessitando de técnicas mais acuradas como microscopia eletrônica de transmissão (MET).

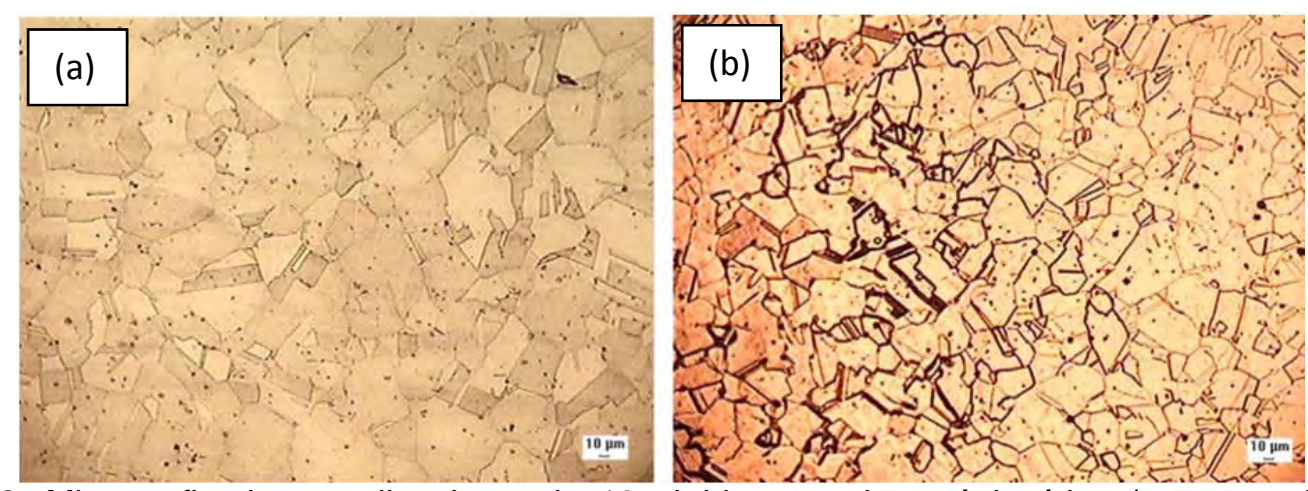

Figura 3. Micrografia da superliga Inconel 718 obtida por microscópio ótico (aumento de 100X). (a) micrografia da superliga como recebida; (b) micrografia da superliga após tratamento de duplo envelhecimento. 


\subsection{Medidas de Microdureza}

A Tabela 2 apresenta os valores médios de microdureza Vickers para as amostras envolvidas neste trabalho.

Tabela 2. Valores de microdureza Vickers

\begin{tabular}{cc}
\hline Amostra (Inconel 718) & Microdureza (HV) \\
\hline Sem o duplo envelhecimento & $240,94 \pm 9,71$ \\
Com o duplo envelhecimento & $469,10 \pm 18,94$ \\
\hline
\end{tabular}

Para a amostra como recebida o valor de microdureza obtido foi de $240,94 \pm 9,71 \mathrm{HV}$. A amostra tratada termicamente apresentou o valor de microdureza de $469,10 \pm 18,94 \mathrm{HV}$. Os valores encontrados no presente trabalho estão de acordo com a literatura. Caliari ${ }^{(7)}$ reportou valores na faixa de 200 e $400 \mathrm{HV}$ para o Inconel 718 e para o tratamento térmico de duplo envelhecimento, respectivamente, utilizando condições muito próximas às realizadas neste trabalho. O aumento na microdureza da amostra tratada por duplo envelhecimento pode ser associado à precipitação de carbetos e formação de novas fases durante o tratamento térmico realizado.

\subsection{Ensaio de Fluência}

A Figura 4 apresenta as curvas de fluência obtidas para a liga Inconel 718 na condição como recebida, denominada neste trabalho de "CR" e após tratamento de duplo envelhecimento, denominada neste trabalho de "EN" na temperatura de $700^{\circ} \mathrm{C}$ e carga constante de $625 \mathrm{MPa}$. Observa-se que o tratamento térmico de duplo envelhecimento para essa temperatura e tensão as diferença geradas não são muito significativas no comportamento da vida em fluência do material, possivelmente, por ser uma condição de alta tensão.

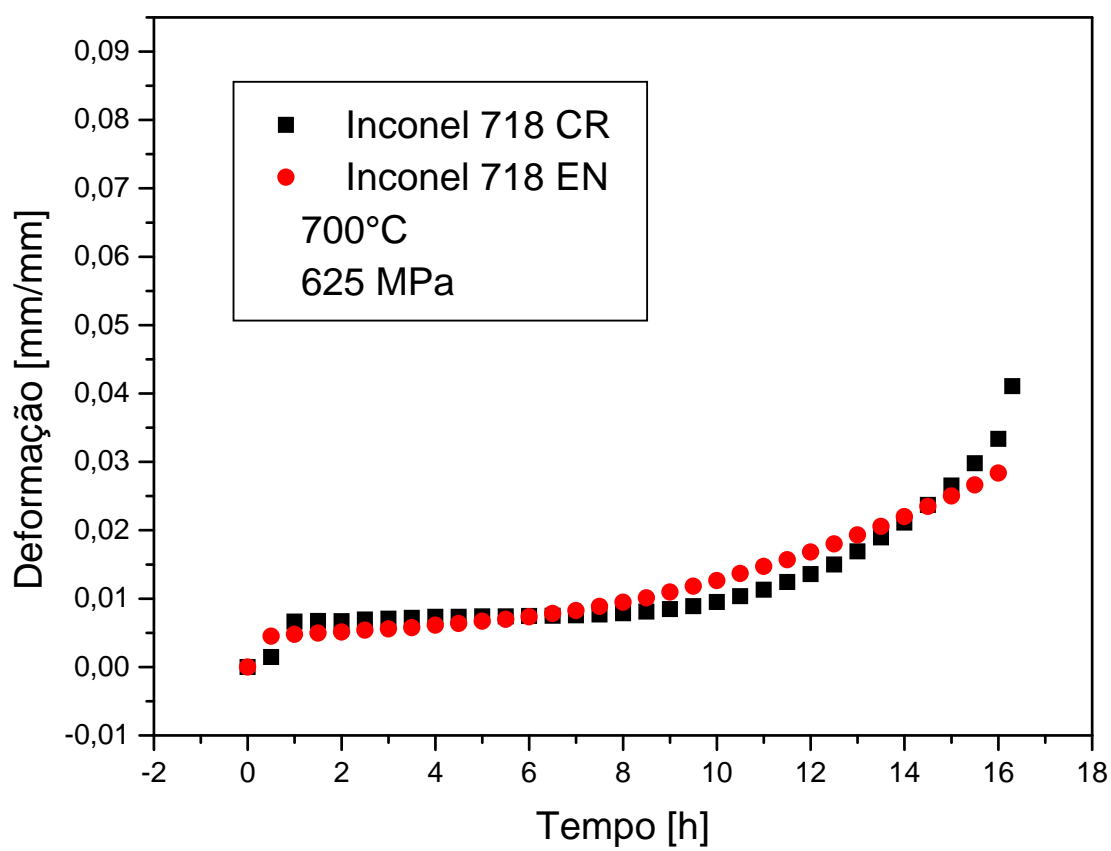

Figura 4. Curva de fluência obtida para a liga Inconel 718 , como recebido e após duplo envelhecimento, em temperaturas de $700^{\circ} \mathrm{C}$ e carga de $625 \mathrm{MPa}$. 
A Tabela 3 apresenta os dados encontrados dos parâmetros de fluência. Podemos observar que a liga tratada termicamente com o duplo envelhecimento mostrou-se com menores valores de tempo primário $\left(t_{p}\right)$, de elongação final $\left(\varepsilon_{f}\right)$ e de taxa de fluência estacionária ( $\dot{\varepsilon}$ ), além de apresentar maior tèsempo de ruptura $\left(\mathrm{t}_{\mathrm{f}}\right)$. Estes fatores indicam o aumento na resistência a fluência, embora não tenha sido muito significativa.

Tabela 3. Parâmetro de fluência

\begin{tabular}{|c|c|c|c|c|c|c|c|}
\hline $\mathrm{T}\left({ }^{\circ} \mathrm{C}\right)$ & Condição & $\sigma(\mathrm{MPa})$ & $\mathrm{t}_{\mathrm{p}}(\mathrm{h})$ & $\dot{\varepsilon}_{s}(1 / \mathrm{h})$ & $\mathrm{t}_{\mathrm{f}}(\mathrm{h})$ & $\begin{array}{c}\varepsilon_{f} \\
(\mathrm{~mm} / \mathrm{mm})\end{array}$ & $\mathrm{RA}(\%)$ \\
\hline 700 & Solubilizada & 625 & 0,5 & $1,26 \mathrm{E}-4$ & 14,37 & 0,04 & 5,0 \\
\hline 700 & $\begin{array}{c}\text { Duplo } \\
\text { envelhecida }\end{array}$ & 625 & 0,4 & $6,05 \mathrm{E}-5$ & 16,30 & 0,02 & 4,6 \\
\hline
\end{tabular}

Com relação à redução em área, a liga tratada termicamente com duplo envelhecimento, apresentou valores menores de redução quando compara com a liga sem o tratamento. Indicando diminuição da ductilidade do material, o que poderia estar contribuindo para o aumento da resistência mecânica. As imagens das fraturas geradas mostram melhor a influencia do duplo envelhecimento sobre o material.

Foram obtidas imagens de fratura do corpo de prova no microscópio eletrônico de varredura modelo FEI Quanta 650 FEG do Centro Nacional de Pesquisa em Energia e Materiais (CNPEM) no Laboratório Nacional de Nanotecnologia (LNNano) de Campinas para observação do tipo de fratura ocorrida.

As Figuras 5 e 6 são referentes à fratura dos corpos de provas de Inconel 718 na condição como recebida ensaiados em fluência na condição de $700^{\circ} \mathrm{C}$ e $625 \mathrm{MPa}$. $\mathrm{Na}$ fratura gerada, observa-se duas regiões distintas, uma caracterizada por fratura frágil com presença de fratura intercristalina, e outra, apresentando características mais dúcteis com presença de alvéolos não profundos.

$\mathrm{Na}$ Figura 5, à esquerda temos a imagem limpa registada pelo MEV e à direita temos a mesma imagem trabalhada para mostrar as porções estimadas de cada tipo de fratura. Na região delimitada pelo contorno azul temos à região de fratura frágil e em vermelho à região de fratura dúctil.
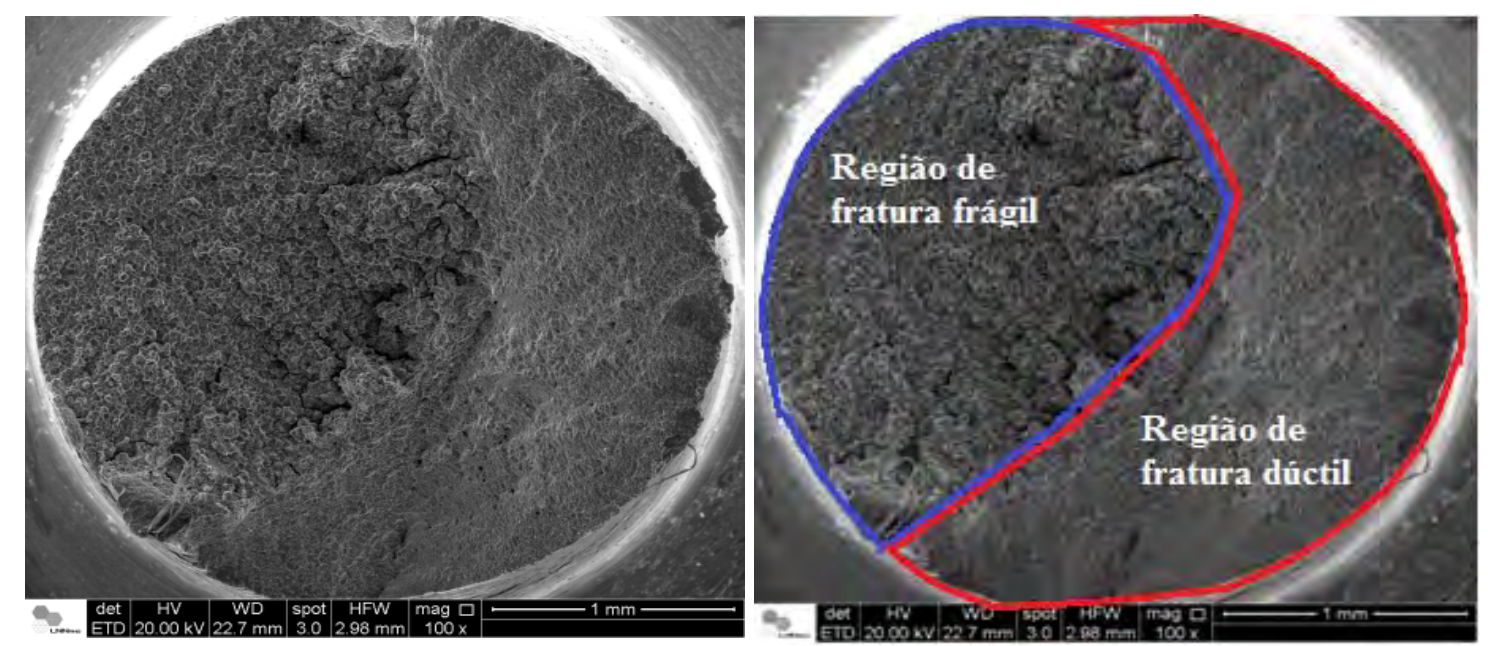

Figura 5. Imagens da fratura do corpo de prova de Inconel 718 sem o duplo envelhecimento. Fluência nas condições de $700^{\circ} \mathrm{C}$ - $625 \mathrm{MPa}$. Aumento de 100x. À direita a imagem limpa e à esquerda a mesma imagem trabalhada. Imagens obtidas do Quanta (MEV) - LNNano/CNPEM. 
Podemos julgar através da imagem que, por estimativa, $50 \%$ das características da fratura são referentes à fratura frágil e que, por estimativa, 50\% das características da fratura são referentes à fratura dúctil.

A Figura 6 apresenta a fratura anterior ampliada com aumento de 500x. Essa imagem mostra melhor as características das duas regiões distintas de fratura da amostra.

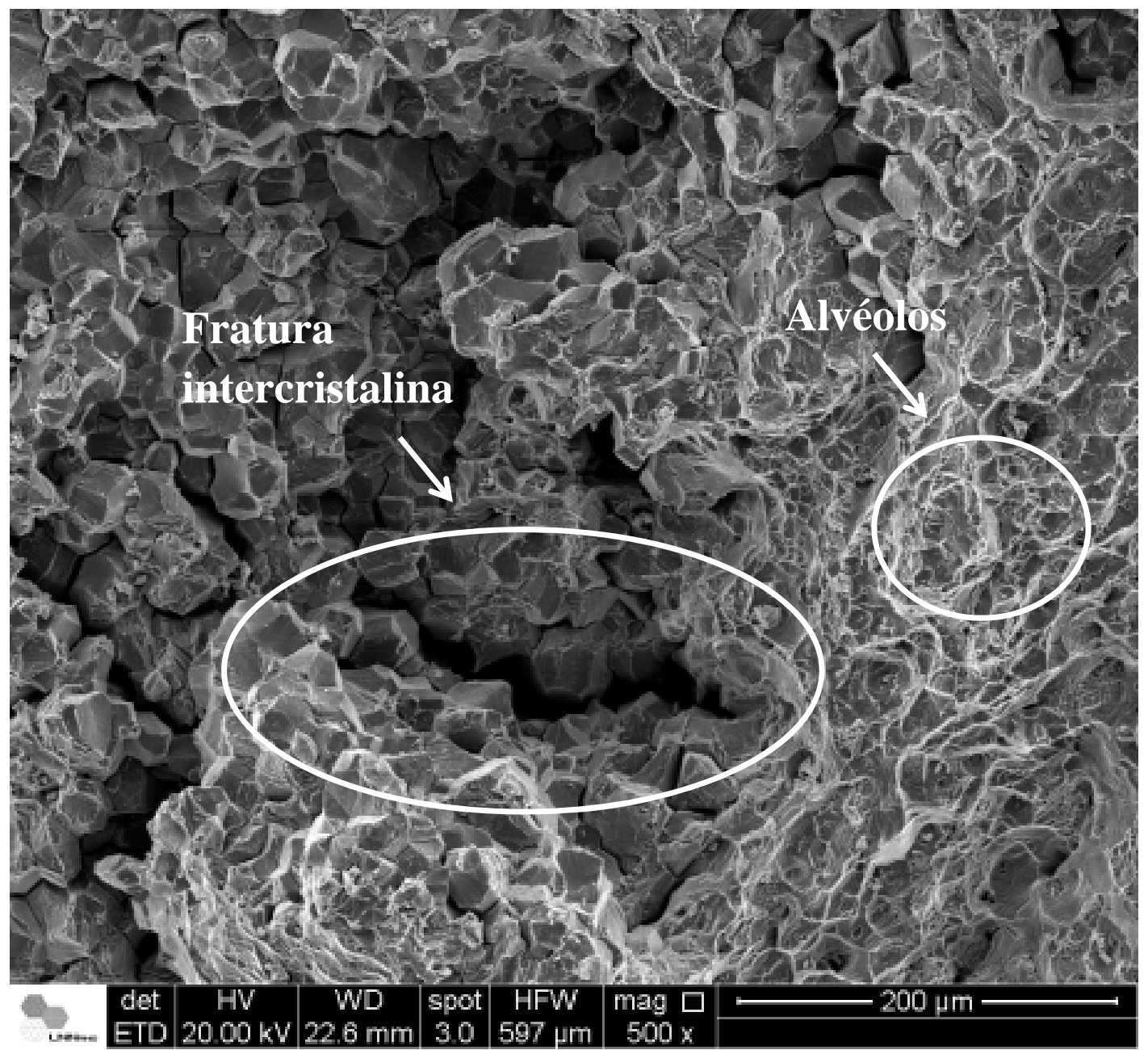

Figura 6. Imagens da fratura do corpo de prova de Inconel 718 como recebida. Fluência nas condições de $700^{\circ} \mathrm{C}$ - $625 \mathrm{MPa}$. Aumento de 500x. Imagens obtidas do Quanta (MEV) LNNano/CNPEM.

As Figuras 7 e 8 são referentes à fratura dos corpos de provas de Inconel 718 tratado termicamente com o duplo envelhecimento, ensaiados em fluência na condição de $700^{\circ} \mathrm{C}$ e $625 \mathrm{MPa}$. Na fratura gerada, também se observa duas regiões distintas, uma caracterizada por fratura frágil com presença de fratura intercristalina, e outra, apresentando características mais dúcteis com presença de alvéolos não profundos e um considerável aumento na quantidade de precipitados.

$\mathrm{Na}$ Figura 7, à esquerda temos a imagem limpa registada pelo MEV e à direita temos a mesma imagem trabalhada para mostrar as porções estimadas de cada tipo de fratura. Na região delimitada pelo contorno azul temos à região de fratura frágil e em vermelho à região de fratura dúctil. 
$68^{\text {th }} \mathrm{abm}$ international annual congress
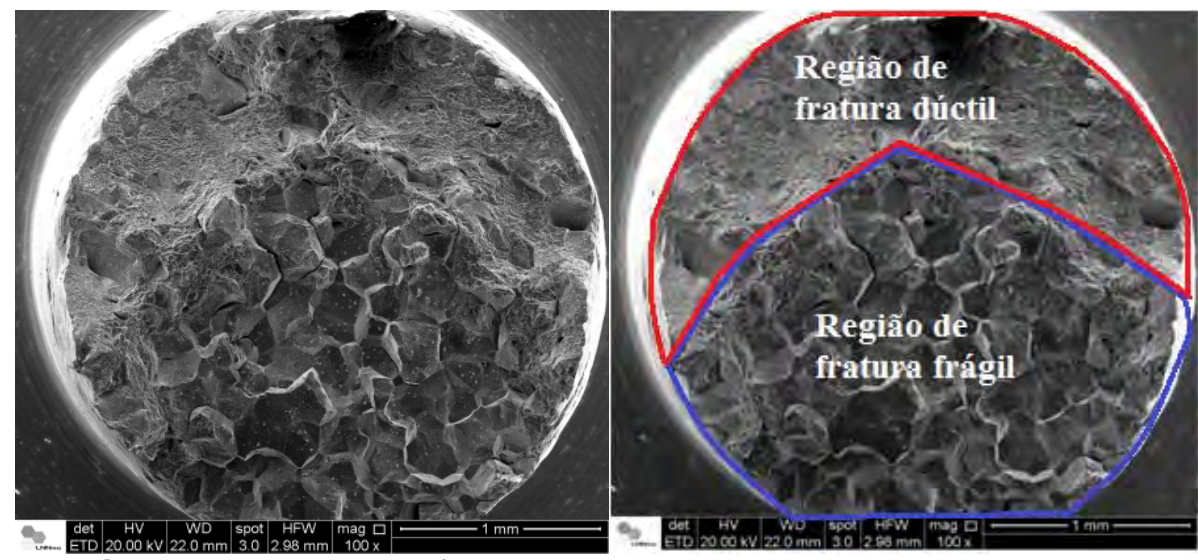

Figura 7. Imagens da fratura do corpo de prova de Inconel 718 sem o duplo envelhecimento. Fluência nas condições de $700^{\circ} \mathrm{C}-625 \mathrm{MPa}$. Aumento de 100x. À direita a imagem limpa e à esquerda a mesma imagem trabalhada. Imagens obtidas do Quanta (MEV) - LNNano/CNPEM.

De acordo com a imagem podemos observar que para a mesma condição de ensaio de fluência, a amostra com o duplo envelhecimento aumentou significativamente a região de fratura frágil. Podemos julgar através da imagem que, por estimativa, $80 \%$ das características da fratura são referentes à fratura frágil e que, por estimativa, $20 \%$ das características da fratura são referentes à fratura dúctil.

A Figura 8 apresenta a fratura anterior ampliada com aumento de 500x. Essa imagem mostra melhor as características das duas regiões distintas de fratura da amostra e o aumento significativo de precipitados na matriz.

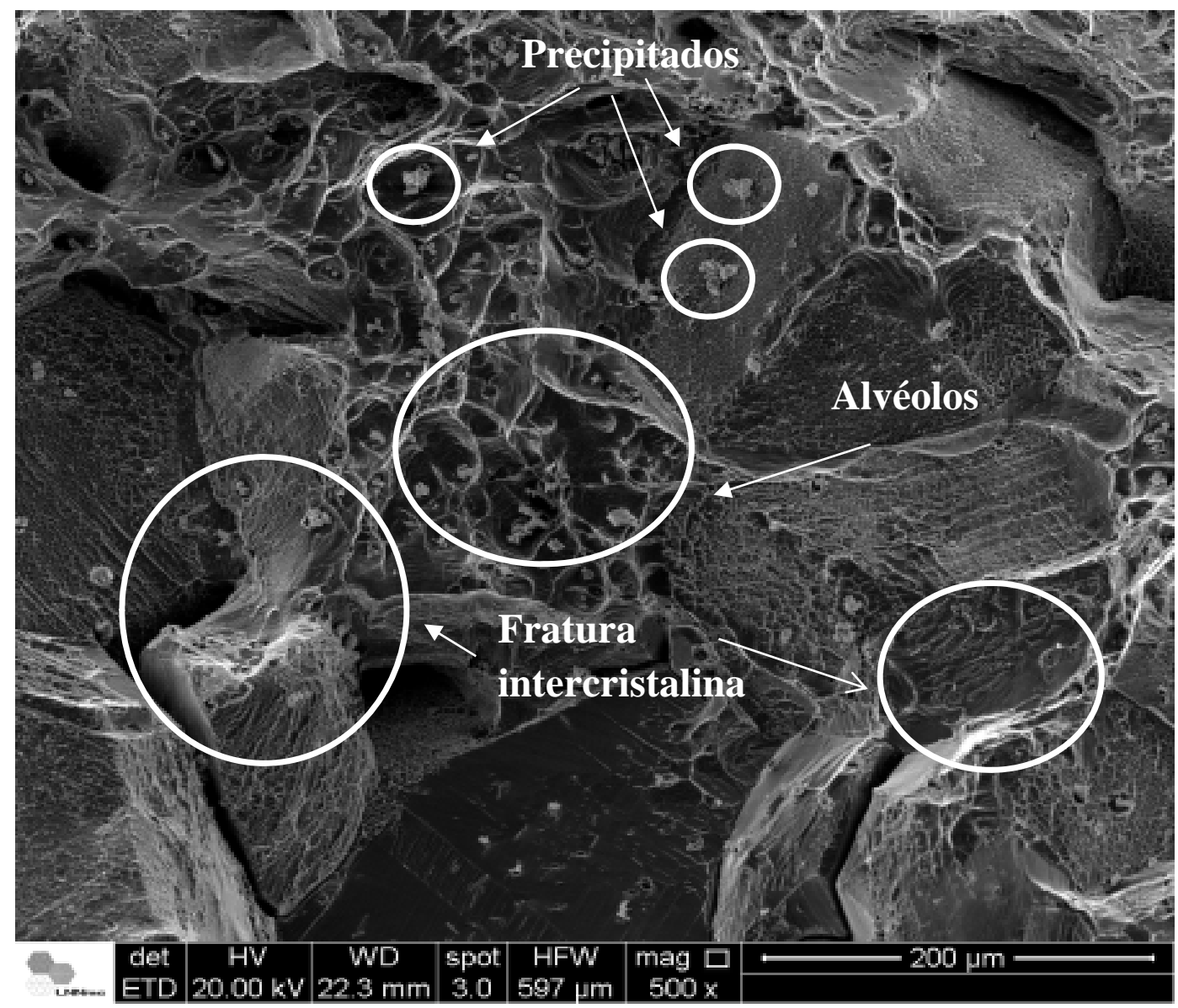

Figura 8. Imagens da fratura do corpo de prova de Inconel 718 duplo envelhecido. Fluência nas condições de $700^{\circ} \mathrm{C}$ - $510 \mathrm{MPa}$. Aumento 500x. Imagens obtidas do Quanta (MEV) LNNano/CNPEM 


\section{DISCUSSÃO}

Através das microestruturas obtidas via microscopia óptica (Figura 3) podemos observar a microestrutura do material. Embora, por meio dessas imagens a precipitação das fases de interesse não fique evidencia, necessitando da aplicação de outra técnica como a microscopia eletrônica de transmissão para isso, ainda sim há possibilidade de observar que o duplo envelhecimento provocou um aumento na quantidade de precipitados nos contornos de grão, possivelmente de carbetos.

Os resultados de fluência são representados por curvas de fluência (Figura 4) apresentando um comportamento típico de fluência, com os três estágios definidos. E pela tabela (Tabela 3) com seus parâmetros evidenciando que o duplo envelhecimento promoveu um leve aumento na resistência à fluência do material. Possivelmente o resultado do duplo envelhecimento não se demostrou muito efetivo devido à aplicação de uma tensão muito alta.

Os valores encontrados de dureza (microdureza Vickers) apresentam um grande aumento para as liga após o duplo envelhecimento, esse resultado evidencia a precipitação de fases que tornam o material mais rígido.

Para estes corpos de prova observa-se fratura do tipo mista. Uma parte caracterizada por fratura frágil com presença de fratura intercristalina, e outra, apresentando características mais dúcteis com presença de alvéolos não profundos. No entanto, a amostra que sofreu o duplo envelhecimento, teve em comparação com a amostra como recebida, um aparente aumento na região de fratura frágil (aumento de 62,5\%) e considerável presença de precipitados. Esse aumento na rigidez e a presença de precipitado tornaram o material duplo envelhecido mais resistente à fluência.

\section{CONCLUSÃO}

Este trabalho apresentou a influência do duplo envelhecimento da 718 sob fluência. Os valores de microdureza Vickers revelaram um grande aumento na dureza do material após duplo envelhecimento (de 240,94 HV para 469,10 HV). Os ensaios realizados geraram curvas apresentando comportamento típico de fluência. Embora, o duplo envelhecimento apresentou uma leve melhora nos resultados de fluência para as condições ensaiada. Possivelmente o ganho de resistência a fluência gerado pelo duplo envelhecimento não se demostrou muito efetivo devido à aplicação de uma tensão muito alta. O tipo de fratura apresentado é característica de fratura mista. A influência do duplo envelhecimento na fluência fica claramente evidencia pelo aumento do campo de região de fratura frágil, aumento de $62,5 \%$ e considerável presença de precipitados. Esse aumento na rigidez e a presença de precipitado, possivelmente, tornaram o material duplo envelhecido mais resistente à fluência.

\section{Agradecimentos}

Ao CNPq, pela concessão da bolsa e apoio financeiro para a realização deste trabalho. Ao Laboratório Nacional de Luz Síncrotron (LNLS - Campinas) pela realização das análises de MEV (Quanta / Projeto 14074). 


\section{REFERÊNCIAS}

1 KUO C.M.; YANG Y.T.; BOR H.Y.; WEI C.N.; TAI C.C., Aging effects on the microstructure and creep behavior of Inconel 718 superalloy, Materials Science and Engineering A 2009.

2 SIMS, T.S, STOLOFF, N., HAGEL W.C. Superalloys II High Temperature Materials for Aerospace and Industrial Power, ed. John Willey, New York,1987.

3 SCHUBERT, F., Temperature and time dependent transformation: Application to heat treatment of high temperature alloys, ASM, Metals Park, 1983, p.3.

4 HEAT TREATER'S GUIDE. Practices and procedures for nonferrous alloys. ASM International, The Materials Information Society. 1996.

5 Specification of nickel base alloy 718(UNS N07718) for oil and gas drilling and production equipment, API specification 6A718, First Edition, Washington, D.C., 2004.

6 ASTM E139/11, Standard Test Methods for Conducting Creep, Creep Rupture, and Stress Rupture Tests of Metallic Materials , 2011.

7 CALIARI, F. R. Avaliação do Comportamento em fluência da superliga Inconel 718 após duplo envelhecimento. Dissertação (Mestrado em Engenharia Aeronáutica e Mecânica) Instituto Tecnológico de Aeronáutica - ITA- São José dos Campos-SP; 2012. 